\title{
KEKUATAN NILAI EMOSIONAL DAN KUALITAS PELAYANAN TERHADAP KEPUASAN KONSUMEN PADA PERUSAHAN JASA EKSPEDISI
}

\author{
Mella Azhar Nisrina ${ }^{1}$, Asep M. Ramdan², Faizal Mulia $Z^{3}$ \\ Program Studi Administrasi Bisnis Universitas Muhammadiyah Sukabumi ${ }^{1,2,3}$ \\ E-mail : mellaazharnisrina12@gmail.com¹,amr37ramdan@gmail.com², \\ paijo_assun@yahoo.com ${ }^{3}$
}

\begin{abstract}
The purpose of this study is measure the influence of emotional value and quality of service on customer satisfaction in expedition service companies. The method used in this study is the use the type of sampling includes in the random sampling sample by distributing 206 questionnaires to consumers. The analysis technique using multiple linear regression analysis techniques, including test coefficient of determination, multiple correlation coefficient, simultaneous test ( $\mathrm{F}$ test), and partial test ( $t$ test). The results of the test coefficient of determination seen from the value (adjusted $\mathrm{R}^{2}$ ) of 0.854 can be interpreted that the effect of Emotional Value and Service Quality on consumer satisfaction is $85.7 \%$. The remaining $14.6 \%$ is influenced by other factors not explained in this study. Based on the multiple correlation coefficient test seen from the $\mathrm{R}$ value of 0.925 , it shows that there is a very strong relationship between emotional value and service quality with customer satisfaction. Based on the $\mathrm{F}$ test the probability value sig. $0.00<0.05$, which means that together Emotional Value (X1) and Service Quality (X2) have a significant effect on customer satisfaction (Y). Based on the $\mathrm{t}$ test shows that Emotional Value (X1) does not have a significant effect on customer satisfaction $(\mathrm{Y})$, Service Quality (X2) has a significant effect on customer satisfaction (Y).
\end{abstract}

Keyword : Emosional Value, service quality, customer satisfaction

\begin{abstract}
ABSTRAK
Tujuan penelitian ini adalah untuk mengukur pengaruh nilai emosional dan kualitas pelayanan terhadap kepuasan konsumen pada perusahaan jasa ekspedisi. Metode yang digunakan dalam penelitian ini adalah menggunakan jenis sampling termasuk kedalam sampel random sampling dengan melakukan penyebaran kuesioner sebanyak 206 kepada konsumen. Teknik analisis yang digunakan adalah teknik analisis regresi linear berganda, termasuk uji koefisien determinasi, koefisien korelasi ganda, uji secara simultan (uji F), dan uji secara parsial (uji t).

Hasil penelitian uji koefisien determinasi dilihat dari nilai (Adjusted $\mathrm{R}^{2}$ ) sebesar 0,854 dapat diartikan bahwa pengaruh Nilai Emosional dan Kualitas Pelayanan terhadap kepuasan konsumen adalah sebesar $85,7 \%$. Sisanya $14,6 \%$ dipengaruhi oleh faktor lainnya yang tidak dijelaskan dalam penelitian ini. Berdasarkan uji koefisien korelasi ganda dilihat dari nilai $\mathrm{R}$ sebesar 0,925, menunjukan bahwa terjadi hubungan yang sangat kuat antara nilai emosional dan kualitas pelayanan dengan kepuasan konsumen. Berdasarkan uji F nilai probabilitas sig. 0,00 $<0,05$ yang berarti bahwa secara bersama-sama Nilai Emosional $\left(\mathrm{X}_{1}\right)$ dan Kualitas Pelayanan $\left(\mathrm{X}_{2}\right)$ berpengaruh secara signifikan terhadap kepuasan konsumen (Y). Berdasarkan uji t menunjukan bahwa Nilai Emosional $\left(\mathrm{X}_{1}\right)$ tidak berpengaruh signifikan terhadap kepuasan konsumen $(\mathrm{Y})$, Kualitas Pelayanan $\left(\mathrm{X}_{2}\right)$ berpengaruh signifikan terhadap kepuasan konsumen (Y).
\end{abstract}

Kata kunci : Nilai emosional, kualitas pelayanan, kepuasan konsumen 


\section{PENDAHULUAN}

Topik penelitian mengenai kepuasan konsumen peneliti mengkaji, selama 20 tahun terakhir. Berdasarkan datanya (J. Joseph Chonen Jr et al., 2002), (Xueming Lue and C.B. Bhattacarya 2006), (Ying-FengKuo 2009), (Kisang Ryu 2012), (Leila AghaKasiri 2017). Badan Pusat Statistik (BPS) pada konferensi pers (2017), menyatakan bahwa pertumbuhan ekonomi nasional dikuartal II-2017 yang sebesar $5,01 \%$ ditopang oleh semua lapang usaha. Untuk sektor lainnya yang menopang pertumbuhan ekonomi dikuartal II-2017 dari jasa lainnya yang sebesar 8,63\% dan sektor jasa perusahaan dengan pertumbuhan $8,14 \%$. Munculnya perusahaan baru dengan produk yang sejenis akan berdampak pada produk, jasa ataupun kualitas yang beragam akan ditawarkan oleh perusahaan (Suhariyanto 2017).

Berdasarkan adanya penelitian mengenai kepuasan pada literatur dengan data berbagai industri, sektor seperti pada jasa ekspedisi (Hanna Ester Novia et al., 2017), (Nurul Hidayah 2018), (Helmy Syamsuri 2015), (Ketut Valien Wira Atmaja et al., 2017), (Alvala Suva 2017). Jasa layanan pengiriman barang atau jasa ekspedisi pada saat ini sudah tersebar di berbagai wilayah di Indonesia dalam memenuhi tingginya kebutuhan hidup masyarakat dalam memenuhi aktivitasnya baik itu perorangan maupun suatu perusahaan. Hal ini menyebabkan adanya perpindahan suatu barang di berbagai tempat. Perusahaan jasa ini menjadi solusi pengiriman secara cepat tanpa membuang waktu yang cukup lama dan pengiriman barang dapat dilakukan secara mudah.

Persaingan yang semakin tinggi sehingga perusahaan dituntut memiliki keunggulan dalam memuaskan konsumennya dengan tujuan untuk mendapatkan 
konsumen yang setia diantara perusahaan lainnya. Dengan adanya perusahaan jasa yang sejenis seperti jasa ekspedisi akan menyebabkan perusahaan berlomba - lomba dalam memperhatikan kualitas pelayanan, kemudahan proses pengiriman barang, kenyamanan dan ketepatan waktu pada pelayanan jasa yang saat atau setelah digunakan oleh konsumen (Riadh Ladhari, 2009), (Mei et al., 1999), (Kandampully dan Suhartanto 2002), (Gounaris et al., 2003).

Masalah yang sering dihadapi perusahaan jasa ekspedisi salah satunya pada kepuasan konsumen. Pada penggunaan jasa ekspedisi para konsumen akan merasa puas saat mendapatkan pengalaman terbaik atau pengalaman positif, permasalahannya seperti belum sepenuhnya konsumen merasakan dan mendapatkan kemudahan, kenyamanan saat pelayanan berlangsung dan kualitas pelayanan yang belum maksimal yang diberikan perusahaan tersebut, seperti pada penyampaian barang masih terkadang tidak tepat waktu, barang diterima dengan keadaan rusak, kurangnya kenyamanan fasilitas seperti tempat untuk menunggu saat proses pelayanan, dan kurangnya daya tanggap pegawai saat penggunaan jasa ekspedisi (Sudarso 2016), (Aisyah 2004: 35).

Tema yang di usulkan ialah Kekuatan Nilai Emosional dan Kualitas Pelayanan Terhadap Kepuasan Konsumen Pada Perusahaan Jasa Ekspedisi. Tujuan Penelitian ini untuk mengukur pengaruh nilai emosional dan kualitas pelayanan terhadap kepuasan konsumen pada perusahaan jasa ekspedisi. 


\section{METODE PENELITIAN}

Penelitian ini dilaksanakan di PT. Dakota Cargo Cabang Sukabumi. Metode yang digunakan dalam penelitian ini adalah menggunakan jenis sampling termasuk kedalam sampel random sampling dan dengan melakukan penyebaran kuesioner sebanyak 206 kepada konsumen. Teknik analisis yang digunakan adalah teknik analisis regresi linear berganda, dan untuk pengujian hipotesis adalah uji statistik secara parsial (uji t) dan uji secara simultan (uji F).

\section{HASIL ANALISIS DATA}

Regresi linear berganda sangat bermanfaat untuk meneliti pengaruh beberapa variabel yang berkorelasi dengan variabel yang diuji. Hasil regresi linear berganda dapat dilihat pada tabel 1 sebagai berikut :

\section{Tabel 1}

\section{Hasil Uji Regresi Linear Berganda}

\begin{tabular}{|c|c|c|c|c|c|c|}
\hline \multicolumn{7}{|c|}{ Coefficients $^{\mathrm{a}}$} \\
\hline \multirow{2}{*}{\multicolumn{2}{|c|}{ Model }} & \multicolumn{2}{|c|}{$\begin{array}{c}\text { Unstandardized } \\
\text { Coefficients }\end{array}$} & \multirow{2}{*}{$\begin{array}{l}\text { Standardized } \\
\text { Coefficients } \\
\text { Beta }\end{array}$} & \multirow{2}{*}{$\mathrm{t}$} & \multirow[b]{2}{*}{ Sig. } \\
\hline & & $\mathrm{B}$ & Std. Error & & & \\
\hline \multirow[t]{3}{*}{1} & (Constant) & ,218 & 269 & & 810 & ,419 \\
\hline & Nilai Emosional & , 106 & ,060 &, 113 & 1,752 & ,081 \\
\hline & $\begin{array}{l}\text { Kualitas } \\
\text { Pelayanan }\end{array}$ & ,220 &, 017 &, 821 & 12,738 & ,000 \\
\hline
\end{tabular}

a. Dependent Variable: Kepuasan Konsumen

Sumber : Data Primer (Kuesioner), 2019

Dari output uji regresi linear berganda diatas, maka dapat diperoleh persamaan sebagai berikut ini :

$$
Y=0,218+0,106 X_{1}+0,220 X_{2}
$$


Tabel 2

Hasil Koefisien Determinasi

\begin{tabular}{lccccc}
\hline \multicolumn{4}{c}{ Model Summary } \\
\hline Model & $\mathrm{R}$ & $\mathrm{R}$ Square & $\begin{array}{c}\text { Adjusted } \mathrm{R} \\
\text { Square }\end{array}$ & $\begin{array}{c}\text { Std. Error of the } \\
\text { Estimate }\end{array}$ \\
\hline 1 &, $925^{\mathrm{a}}$ &, 856 &, 854 &, 992 \\
\hline
\end{tabular}

Sumber : Data Primer (Kuesioner), 2019

Hasil tabel 2 diatas model summary besarnya adjusted $R^{2}$ adalah 0,854 ; hal ini berarti $85,4 \%$ variasa kepuasan konsumen dapat dijelaskan oleh variasi dari dua variabel independen nilai emosional dan kualitas pelayanan sedangkan sisanya $14,6 \%(100 \%-85,4 \%=14,6 \%)$ dari faktor yang tidak diteliti.

Tabel 3

\section{Hasil Koefisien Korelasi Ganda}

Model Summary

\begin{tabular}{|c|c|c|c|c|}
\hline Model & $\mathrm{R}$ & R Square & $\begin{array}{c}\text { Adjusted R } \\
\text { Square }\end{array}$ & $\begin{array}{l}\text { Std. Error of the } \\
\text { Estimate }\end{array}$ \\
\hline 1 &, $925^{\mathrm{a}}$ & ,856 & ,854 & ,992 \\
\hline
\end{tabular}

Berdasarkan tabel 3 di atas dipeoleh angka R sebesar 0,925 berada pada katagori 0,60-0,799. Hal ini menunjukan bahwa terjadi hubungan yang sangat kuat antara nilai emosional dan kualitas pelayanan dengan kepuasan konsumen. 
Tabel 4

Hasil Uji F

\begin{tabular}{rlrrrrr}
\hline \multicolumn{7}{c}{ ANOVAa } \\
\hline \multirow{2}{*}{ Model } & Sum of & & & & & \\
\hline 1 & Regression & Squares & df & Mean Square & F & Sig. \\
& Residual & 1184,132 & 2 & 592,066 & 602,222 &, $000^{\mathrm{b}}$ \\
& Total & 199,577 & 203 &, 983 & & \\
\cline { 2 - 6 } & 1383,709 & 205 & & & \\
\hline
\end{tabular}

a. Dependent Variable: Kepuasan Konsumen

b. Predictors: (Constant), Kualitas Pelayanan, Nilai Emosional

Sumber : Data Primer (Kuesioner), 2019

Berdasarkan tabel 4 di atas, hasil uji F yang dilakukan dapat diperoleh nilai sig. $0,000<0,05$; nilai $F_{\text {hitung }} 602.222>F_{\text {tabel }}$ 3,88. Artinya bahwa nilai emosional dan kualitas pelayanan secara sama-sama (simultan) berpengaruh terhadap kepuasan konsumen.

Tabel 5

Hasil Uji t

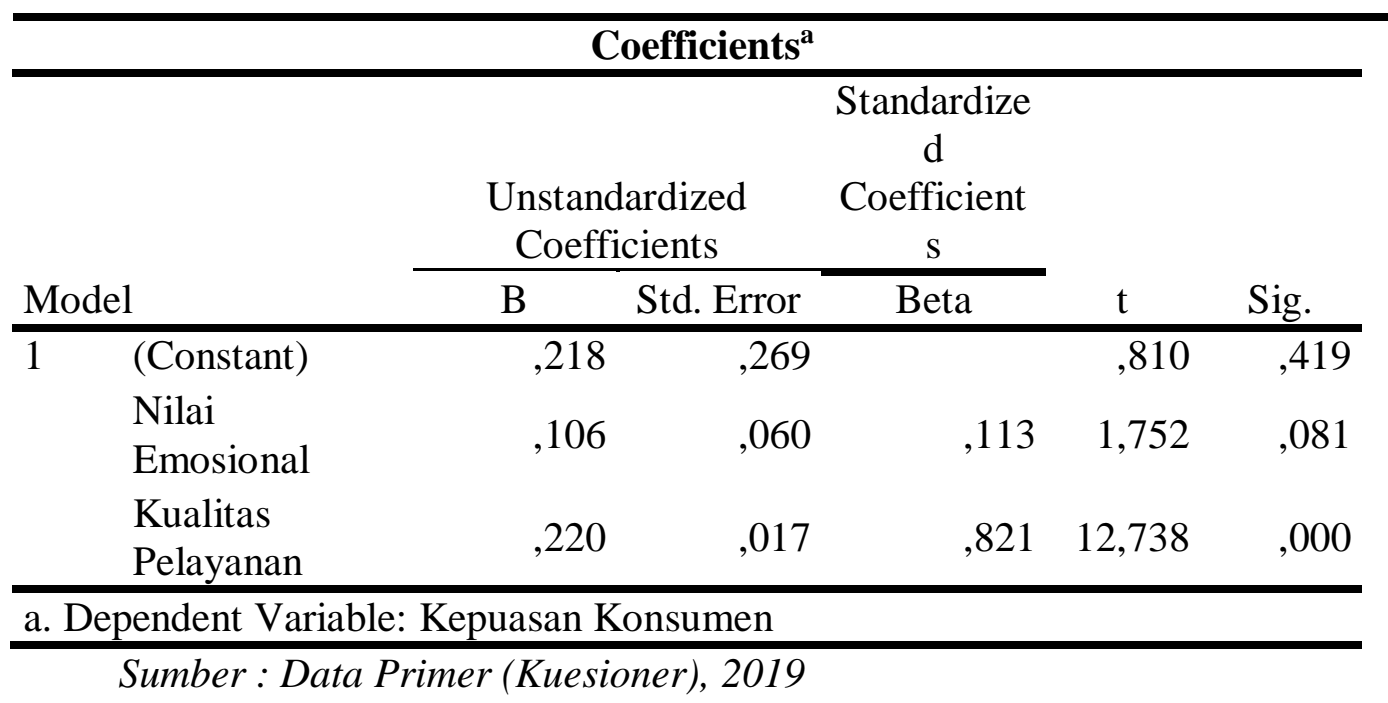

Berdasarkan tabel 5 di atas, hasil uji hipotesis uji t yang dilakukan dapat dilihat bahwa variabel nilai emosional nilai sig. $0,081>0,05$; nilai thitung $1.752<t_{\text {tabel }}$ 
1.9717, artinya nilai emosional tidak berpengaruh signifikan secara parsial. Variabel kualitas pelayanan nilai sig $0,000<0,05$; nilai $\mathrm{T}_{\text {hitung }} 12.738>\mathrm{t}_{\text {tabel }} 1.9717$, artinya kualitas pelayanan berpengaruh positif dan signifikan secara parsial terhadap kepuasan konsumen.

\section{PEMBAHASAN}

$\mathrm{H}_{1}$ : Nilai emosional berpengaruh terhadap kepuasan konsumen pada perusahaan jasa ekspedisi.

$\mathrm{H}_{0}$ : Tidak adanya pengaruh signifikan antara nilai emosional terhadap kepuasan konsumen pada perusahaan jasa ekspedisi.

Ha : Adanya pengaruh positif dan signifikan antara nilai emosional terhadap kepuasan konsumen pada perusahaan jasa ekspedisi.

Nilai emosional tidak berpengaruh positif dan signifikan terhadap kepuasan konsumen (Y) secara parsial. Hal ini dibuktikan dari hasil pengujian uji $t$ menunjukan nilai sig. $0,081>0,05$; nilai $t_{\text {hitung }} 1.752<t_{\text {tabel }} 1.9717$, maka dapat disimpulkan bahwa $\mathrm{H}_{a}$ ditolak dan $\mathrm{H}_{0}$ diterima. Maka menunjukan bahwa nilai emosional pada perusahaan jasa eskpedisi memberikan nilai negatif dalam mempengaruhi kepuasan pada konsumen.

$\mathrm{H}_{2}$ : Kualitas pelayanan berpengaruh terhadap kepuasan konsumen pada perusahaan jasa ekspedisi. 
$\mathrm{H}_{0}$ : Tidak adanya pengaruh signifikan antara kualitas pelayanan terhadap kepuasan konsumen pada perusahaan jasa ekspedisi.

Ha: Adanya pengaruh positif dan signifikan antara kualitas pelayanan terhadap kepuasan konsumen pada perusahaan jasa ekspedisi.

Kualitas pelayanan berpengaruh positif dan signifikan terhadap kepuasan konsumen (Y) secara parsial. Hal ini dibuktikan dari hasil pengujian uji t menunjulan nilai sig. $0,000<0,05$; nilai $\mathrm{T}_{\text {hitung }} 12.738>\mathrm{t}_{\text {tabel }} 1.9717$, maka dapat disimpulkan bahwa $\mathrm{H}_{0}$ ditolak dan $\mathrm{H}_{\mathrm{a}}$ diterima. Maka menunjukan bahwa kualitas pelayanan pada perusahaan jasa ekspedisi memberikan nilai positif dalam mempengaruhi kepuasan pada konsumen.

$\mathrm{H}_{3}$ : Nilai emosional dan kualitas pelayanan berpengaruh terhadap kepuasan konsumen pada perusahaan jasa ekspedisi.

$\mathrm{H}_{0}$ : Tidak adanya pengaruh signifikan antara nilai emosional kualitas pelayanan terhadap kepuasan konsumen pada perusahaan jasa ekspedisi.

Ha : Adanya pengaruh positif dan signifikan antara nilai emosional dan kualitas pelayanan terhadap kepuasan konsumen pada perusahaan jasa ekspedisi.

Nilai emosional dan kualitas pelayanan berpengaruh positif dan signifikan terhadap kepuasan konsumen (Y) secara simultan. Hal ini dibuktikan dari hasil pengujian uji $\mathrm{F}$ menunjukan nilai sig $0,000<0,05$; nilai $\mathrm{F}_{\text {hitung }} 602.222>\mathrm{F}_{\text {tabel }} 3,88$, maka dapat disimpulkan bahwa $\mathrm{H}_{3}$ diterima dan $\mathrm{H}_{0}$ ditolak. Menyimpulkan bahwa 
nilai emosional dan kualitas pelayanan berpengaruh signifikan secara bersamasama (simultan) terhadap kepuasan konsumen.

Berdasarkan pada hasil analisis regresi berganda uji $\mathrm{F}$ dengan tingkat signifikan sebesar 0,05 (5\%) menunjukan bahwa variabel Nilai Emosional $\left(\mathrm{X}_{1}\right)$ dan Kualitas Pelayanan $\left(\mathrm{X}_{2}\right)$ berpengaruh secara bersama-sama terhadap Kepuasan Konsumen (Y). Hal ini ditunjukan dengan hasil nilai sig $0,00<0,05$ dan nilai $F_{\text {hitung }}$ 602.222 $>\mathrm{F}_{\text {tabel }}$ 3,88. Nilai Koefisien determinasi $\left(\mathrm{R}^{2}\right)$ diperoleh hasil dari variabel Nilai Emosional $\left(\mathrm{X}_{1}\right)$ dan Kualitas Pelayanan $\left(\mathrm{X}_{2}\right)$ mempengaruhi sebesar 0,854 $(85,4 \%)$ terhadap Kepuasan Konsmen (Y), sisanya 14,6\% dari faktor yang tidak bahas dan diteliti. Hal ini dapat disimpulkan bahwa konsumen akan merasa puas serta mendorong mereka untuk merasa puas atas keseluruhan layanan dengan Nilai Emosional (perasaan positif) yang dirasakan seperti mendapatkan pengalaman terbaik, merasakan keadilan pelayanan, merasakan kemudahan dan kecepatan pelayanan saat menggunakan jasa, serta konsumen mendapatkan kualitas pelayanan maksimal yang diberikan perusahaan dalam memenuhi kebutuhannya seperti dalam hal jaminan, keandalan, bukti fisik, empati, dan daya tanggap, yang diberikan oleh PT. DAKOTA Cargo Cabang Sukabumi.

Pengaruh Nilai Emosional $\left(\mathrm{X}_{1}\right)$ terhadap Kepuasan Konsumen $(\mathrm{Y})$ berdasarkan hasil analisis data yang didapat pada uji t Nilai Emosional $\left(\mathrm{X}_{1}\right)$ dengan Kepuasan konsumen (Y) menunjukan bahwa nilai thitung sebesar 2.410 sedangkan $\mathrm{t}$ tabel $(\alpha=$ $0,05)$ diperoleh hasil $t_{\text {tabel }} 1.9717$. Nilai signifikasi yang didapat $0,081>0,05$ dan nilai thitung $1.752<\mathrm{t}_{\text {tabel }} 1.9717$ maka pengaruh $\left(\mathrm{X}_{1}\right)$ terhadap $(\mathrm{Y})$ tidak signifikan. 
Dapat disimpulkan bahwa Nilai Emosional tidak berpengaruh signifikan terhadap Kepuasan Konsumen. Hal ini menunjukan bahwa konsumen saat mereka menggunakan jasa layanan ekspedisi, nilai emosional tidak menjadi alasan mereka dalam menggunakan jasa ekspedisi dalam memenuhi kebutuhannya. Kemampuan pegawai dalam memberikan pengalaman terbaik, keadilan pelayanan, kemudahan dan kecepatan saat layanan yang diberikan belum mampu membentuk kepuasan bagi konsumen PT. DAKOTA Cargo Cabang Sukabumi.

Pengaruh Kualitas Pelayanan $\left(\mathrm{X}_{2}\right)$ terhadap Kepuasan Konsumen (Y)

Berdasarkan hasil analisis data yang didapat pada uji t Kualitas Pelayanan $\left(\mathrm{X}_{2}\right)$ dengan Kepuasan konsumen (Y) menunjukan bahwa nilai thitung sebesar 13.090 sedangkan $\mathrm{t}$ tabel $(\alpha=0,05)$ diperoleh hasil $\mathrm{t}_{\text {tabel }} 1.9717$. Nilai signifikasi yang didapat $0,00<0,05$; nilai $\mathrm{T}_{\text {hitung }} 12.738>\mathrm{t}_{\text {tabel }} 1.9717$ maka pengaruh $\left(\mathrm{X}_{2}\right)$ terhadap (Y) signifikan. Dapat disimpulkan bahwa Kualitas Pelayanan berpengaruh signifikan terhadap Kepuasan Konsumen. Hal ini menunjukan bahwa konsumen yang memberikan tanggapan baik terhadap kualitas pelayanan yang baik dalam hal jaminan, keandalan, bukti fisik, empati, dan daya tanggap mendorong mereka merasa puas atas keseluruhan layanan jasa PT. DAKOTA Cargo Cabang Sukabumi, merasakan bahwa jasa ekspedisi PT. DAKOTA Cargo Cabang Sukabumi mampu memberikan layanan nyata sesuai dengan harapan dan merasa senang atas layanan yang diberikan oleh PT. DAKOTA Cargo Cabang Sukabumi. 


\section{SIMPULAN}

Secara parsial, Nilai emosional tidak berpengaruh positif dan signifikan terhadap kepuasan konsumen pada jasa ekspedisi PT. DAKOTA Cargo Cabang Sukabumi. Secara parsial, kualitas pelayanan berpengaruh positif dan signifikan terhadap kepuasan konsumen pada jasa ekspedisi PT. DAKOTA Cargo Cabang Sukabumi. Berdasarkan uji F, variabel nilai emosional dan kualitas pelayanan berpengaruh signifikan secara bersama-sama (simultan) terhadap kepuasan konsumen pada jasa ekspedisi PT. DAKOTA Cargo Cabang Sukabumi.

\section{REFERENSI :}

Alvala el al.,, (2017), Pengaruh Kualitas Pelayanan dan Kepuasan Terhadap Loyalitas Konsumen Melalui Kepercayaan Sebagai Variavel Intervening (Studi kasus CV. TIKI Padang Jl. Nipah No. 48), 2017.

Arindiaty, Adsty Dan Merita, (2017), Analisis Kualitas Jasa Dalam Meningkatkan Kepuasan Konsumen Di Baker Street Cafe Bandung, Jurnal Bisnis Terapan, 1, (1), Juli 2017, $2580-4928$.

Atmojo, Prw, dan Nindria,(2014), Pengaruh Kualitas Layanan Dan Emosional terhadap Kepuasan Penumpang Kereta Api Ekonomi Ac Majapahit, Jurnal Ilmu Manajemen, 2, (4), Oktober 2014.

Apriani, DA, dan Surnarti, (2017), Pengaruh Kualitas Pelayanan Terhadap Kepuasan Konsumen (Survei pada Konsumen The Little A Coffee Shop Sidoarjo), Jurnal Administrasi Bisnis, 51, (2).

Christianingrum, (2016), Pengaruh Implementasi Experiential Marketing Terhadap Loyalitas Member Salon Humaira, Jurnal Pendidikan Manajemen Bisnis, 11, (19).

Farratmata, Ldt, (2013), Pengaruh Kualitas Layanan dan Nilai Emosional Konsumen Terhadap Kepuasan Konsumen Jasa Mobile Pada Telkomsel Jabotabek Area, Tesis Manajemen, 3884.

Helmy Syamsuri, (2015), Pengaruh Tarif dan Kepuasan Pelanggan Terhadap Jasa Pengiriman Barang pada PT. TIKI Jalur Nugraga Ekakurir Cabang Makasar, 5.(2), 1-12.

Istiqo, M, Ctr. dan Poernomo, Edy, (2017), Pengaruh Kualitas Pelayanan, Harga, Dan Faktor Emosional Terhadap Kepuasan Konsumen Pada Hotel The Sun Sidoarjo, Jurnal Bisnis Indonesia, 8, (1). 
Iwan, (2015), Pengaruh Emotion Marketing Terhadap Keputusan Pembelian Produk Tupperware (Studi pada Pelanggan Tupperware di Kabupaten Purworejo), Jurnal Ekonomi.

J.Joseph CroninJr et al., (2000), Assessing the effects of quality, value, and customer satisfaction on consumer behavioral intentions in service environments, Journal of Retailing, 76, (2), 193-218.

Katerina Berezina et al., (2012), The Impact Of Information Security Breach On Hotel Guest Perception Of Service Quality, Satisfaction, Revisit Intentions and Word-Of-Mouth, International Journal of Contemporary Hospitality Management, 24, (7).

Ketut et al.,,(2017), Pengaruh Kualitas Pelayanan dan Kepuasan Terhadap Loyalitas Pelanggan pada PT. Pos Cabang Singaraja, 10, (2).

Kisang Ryu et al.,, (2012), The influence of the quality of the physical environment, food, and service on restaurant image, customer perceived value, customer satisfaction, and behavioral intentions, International Journal of Contemporary Hospitality Management, 24, (2), 200-223.

Kotler, dan Keller,. 2012. Manajemen Pemasaran. Edisi 12. Jakarta : Penerbit Erlanggan.

Leila et al.,, (2017), "ntegration of standardization and customization: Impact on service quality, customer satisfaction, and loyalty, 35, 91-97

Muhammad Ali \& Syed Ali Raza, (2015), Service quality perception and customer satisfaction in Islamic banks of Pakistan: the modified SERVQUAL model, Original Articles, Pages 559-577.

Hanna et al.,, (2017), Pengaruh Kualitas Pelayanan dan Harga Terhadap Kepuasan Pelanggan Pada Expedisi di Pekanbaru (Studi PT. JNE (Jalur Nugraha Ekakurir) Pekanbaru), Journal FISIP,4, (2).

Nurul Hidayah, (2018), Analisis Kepuasan Konsumen Jasa Pengiriman Barang J\&T Ekspress Ditinjau dari Kualitas Pelayanan, Fasilitas, dan Harga, Artikel Skripsi.

Octoria Sidabutar, Sndy, Suharyono, dan Kusumawati, Adrni, (2016), Pengaruh Experiental Marketing Dan Emotional Marketing Terhadap Keputusan Pembelian (Survei Konsumen Sepatu NIKE Di Indonesia dan Di Malaysia), Jurnal Administrasi Bisnis,39, (2).

Pawestriningtyas, NC, Suharyono, dan Suyadi, Imn, (2016), Pengaruh Kualitas Pelayanan Jasa Terhadap Kepuasan Nasabah (Survei Pada Nasabah Perum Pegadaian Kantor Cabang Syariah Tlogomas Malang), Jurnal Administrasi Bisnis, 32, (2).

Riadh Ladhari, (2009), Service Quality, Emotional Satisfaction, and Behavioural Intentions A Study In The Hotel Industry, International Journal Of Busines Administration, 19, (3). 
Sudarso, Erk, (2016), Kualitas Layanan, Nilai Fungsional, Nilai Emosional dan Kepuasan Konsumen: Sebuah Studi Kasus, Jurnal Ekonomi Bisnis dan Kewirausahaan, 5, (3), 165-178.

Sangadji, dan Sopiah.,. 2013. Perilaku Konsumen. Yogyakarta : Penerbit Andi.

Sugiyono,. 2013. Metode Penelitian Kuantitatif, Kualitatif dan $R \& D$. Bandung :Alfabeta.

Tjiptono, Fandy dan Gregorius Chandra.,. 2012. Pemasaran Strategik. Yogyakarta : Penerbit Andi.

Wibowo, AS, 2013, Pengaruh Harga, Kualitas Pelayanan dan Nilai Konsumen Terhadap Kepuasan Konsumen Pada Rumah Makan Di Kota Purwokerto, Skripsi.

Winarti, Eis, Dan Tiffany (2016), Antara Kualitas Pelayanan Jasa Ekspedisi Dengan Loyalitas Konsumen, 5, (2), November 2016, 2252-9993.

Xueming Luo and C.B. Bhattacharya (2006), Corporate Social Responsibility, Customer Satisfaction, and Market Value, Journal of Marketing, 70, (4), 1-18.

Ying et al.,, (2009), The relationships among service quality, perceived value, customer satisfaction, and post-purchase intention in mobile value-added services, Journal Computers in Human Behavior, 25, (4), 887-896.

Yuniar, Vrz, dan Setyorini, Rtn, (2015), Pengaruh Kualitas Pelayanan Terhadap Kepuasan Konsumen Pada Perusahaan Jasa EMKL Saputra Trans Abadi Cirebon, Jurnal e-Proceeding of Management, 2, (3), 